\title{
A comparative study on the role of oral mifepristone and endocervical prostaglandin as preinduction cervical ripening agent
}

\author{
Sanghamitra Mohapatra, Samarpita*
}

Department of Obstetrics and Gynecology, M.K.C.G Medical College, Berhampur, Odisha, India

Received: 08 October 2020

Revised: 17 November 2020

Accepted: 02 December 2020

\section{*Correspondence:}

Dr. Samarpita,

E-mail: samarpita024@ gmail.com

Copyright: ( $\odot$ the author(s), publisher and licensee Medip Academy. This is an open-access article distributed under the terms of the Creative Commons Attribution Non-Commercial License, which permits unrestricted non-commercial use, distribution, and reproduction in any medium, provided the original work is properly cited.

\begin{abstract}
Background: Induction of labour is one of the most common interventions practised in modern obstetrics with up to $20 \%$ of pregnant women having labour induced in some countries. Induction rates have been influenced by several reports worldwide, which claimed that an active induction policy, led to substantial reduction in perinatal and maternal morbidity and mortality. A ripe or favourable cervix is a pre-requisite for successful vaginal birth. This study is conducted with an aim to compare the efficacy of mifepristone and dinoprostone as a cervical ripening and priming agent for induction of labour and their safety and fetomaternal outcome.

Methods: It was a prospective comparative study in the Department of Obstetrics and Gynecology, M.K.C.G. Medical college, Berhampur from October 2017 to October 2019. 100 cases with bishop score less than 6 were subjected for pre induction ripening. These cases were assigned at random either to study group, who were given single dose oral mifepristone $200 \mathrm{mg}$ and control group with single dose intracervical E2 gel. All the cases were examined to check the bishop score. In cases of control cases, second dose was given after 6 hours, if there was no improvement in bishop score. At the end of 24 hour if bishop score $<6$, it was called as failed induction.

Results: $90 \%$ of mifepristone gr and $56 \%$ of dinoprostone gr had improved Bishop score $>6$ after $6 \mathrm{hr} .32$ cases required oxytocin augmentation in mifepristone gr where as it was 57 in dinoprostone. Drug administration to delivery interval was 19.40 hour in mifepristone gr and 15 hour in dinoprostone gr. More vaginal delivery and less fetal distress in mifepristone gr.

Conclusions: Mifepristone is an effective agent for cervical ripening with better fetomaternal outcome compaired to dinoprostone.
\end{abstract}

Keywords: Dinoprostone, Mifepristone, Preinduction cervical ripening

\section{INTRODUCTION}

Human parturition has been termed 'labour' in recognition of the hard work that the parturient as well as the uterine myometrium have to perform in order to deliver the fetus. Labour refers to the onset of effective uterine contractions leading to progressive effacement and dilatation of the cervix resulting in the expulsion of the fetus, placenta and the membranes. ${ }^{1}$ Cervical ripening is a process by which the cervix becomes soft, compliant and partially dilated. It is due to a combination of biochemical, endocrine, mechanical and possibly inflammatory events.

In the present world, there is a spectrum of valid indications for induction of labour. The concept of elective induction for the convenience of the obstetrician and the patient, is not recommended by the ACOG at present, but this practice is recommended or indicated when the benefits for the mother and fetus outweigh 
those of continuing the pregnancy and to achieve vaginal delivery, thus avoiding an unnecessary caesarean section. $^{2}$ Favourability of the cervix is a need for labour induction. Research in this direction has helped in the development of various methods to 'ripen' the cervix prior to uterine contractions. The discovery of prostaglandins, and lately the antiprogesterones, have made labour induction at the disposal of the obstetrician, enabling the delivery of the patient as and when required, thus allowing a carefully planned active management, and in bringing down the trauma of a prolonged or protracted and painful labour for the patient, to give her a healthy baby without compromising her.

Mifepristone is a 19 nor Steroid with a greater affinity for the progesterone receptor and thus blocks the action of progesterone at a cellular level. As a fall in the level of progesterone considered one of the important events in the onset of spontaneous labour, it therefore seems likely that this drug may be useful on induction. ${ }^{3}$ The pharmacokinetics of mifepristone is characterized by rapid absorption and a long half-life of 25-30 hour. ${ }^{4}$ Dinoprostone is a naturally occurring prostaglandin E2 (PGE2). Prostaglandins allow for an increase in intracellular calcium levels, causing contraction of myometrial muscle. Dinoprostone Gel (cerviprime gel) is a prostaglandin E2. Fetal membranes (amnion) produce prostaglandin E2. It acts mainly on the cervix due to its collagenolytic property and has an oxytocic effect on the pregnant uterus when used in appropriate dose, stimulates labour and delivery and thus terminates pregnancy. Dinoprostone also is capable of stimulating the smooth muscles of gastrointestinal tract. Objective was to compare the efficacy of mifepristone and dinoprostone as a cervical ripening and priming agent for induction of labour and to study safety and fetomaternal outcome after the use of mifepristone versus dinoprostone.

\section{METHODS}

This prospective comparative study was done in the Department of Obstetrics and Gynecology, M.K.C.G. Medical College, Berhampur from October 2017 to October 2019. 100 antenatal women were selected for study 50 women received oral mifepristone $200 \mathrm{mg}$ and 50 women received endocervical PGE2 gel $0.5 \mathrm{mg}$.

\section{Inclusion criteria}

Singleton pregnancy with cephalic presentation and intact membranes if labour induction was indicated and delivery could be postponed for 24 hours. Women with unfavourable cervix (Bishop score less than 6). Valid indication for induction of labour.

\section{Exclusion criteria}

Known hypersensitivity to prostaglandins or mifepristone. Medical problems like impaired renal, hepatic or adrenal function. All cases where vaginal delivery is not indicated.

On admission, a detailed history, and complete general and obstetric examination was carried out. Vaginal examination was done under strict aseptic precautions and the cervical status, fetal station were assessed. Gestational age calculated by Naegle's rule and a routine obstetric scan for fetal maturity and well-being was done. Once the inclusion criteria were fulfilled and cephalopelvic disproportion was ruled out.

Out of 100, 50 pregnant women were given tablet mifepristone $200 \mathrm{mg}$ orally and other 50 were instilled endocervical PGE2 gel $0.5 \mathrm{mg}$. They were observed for maternal vitals, uterine activity, bleeding or draining pv and fetal heart rate. After the wait period of 24 hours or when the Bishop score was $\geq 6$ or when the membranes ruptured or when the patient was well in labour whichever is earlier labour was accelerated with oxytocin drip. 2nd dose of PGE2 will be given after 6 hours, if there will be no improvement in bishop's score.

The efficacy was assessed by favourability of Bishop score at 24 hours, need of oxytocin for augmentation, duration of 1 st, 2nd and 3rd stage of labour, drug administration to delivery interval, mode of delivery, Csection rate, Apgar score, neonatal complications, maternal complications.

\section{Success of induction was assessed by the following criteria}

Bishop score of $\geq 6$ at the end of 24 hours

\section{Failure of induction was assessed by the following criteria}

Bishop score of $<6$ at end of 24 hours

\section{RESULTS}

Most of the cases were 20-29 years of age and least were $\geq 35$ year in both groups. Age and parity distributions of women included in this study were comparable in both mifepristone and PGE2 gel group. In maximum cases, induction was done at $>40$ week $(56 \%$ in group I verses $60 \%$ in group II). The major indication for induction was post-dated pregnancy without any risk factors, 16 cases $(32 \%)$ in gr-I and 17 cases (34\%) in gr-II. For oligohydramnious, 15 and 13 cases were induced in gr-I and gr-II respectively. Other indications for induction were FGR, twin (1st twin vertex), IUFD, GDM with controlled sugar, PIH and congenital anomaly (Table 1).

Maximum mothers in both the groups had initial bishop's score of 2 to 5 before preinduction cervical ripening. Only 1 primi in gr-I had 0 Bishop score. P-value for Bishop's score at start 0.169 which is not significant (Table 2). After 6 hour 5 cases in gr-I and 22 cases in gr- 
II still had Bishop's score $<6$. So, in $90 \%$ of gr-I and $56 \%$ of gr-II have improved Bishop score $>6$ (Table 3).

In gr-I, the rate of improvement in Bishop's score was satisfactory, i.e. 6.24 at 6 hour, 9.43 in 12 hour and 10 in 24 hour. Only 1 patient was having Bishop's score 5 at 24 hour undergone CS due to failed induction in gr-I. In grII, the mean Bishop's score at 6 hour, 12 hour and 24 hour were 5.96, 9.93 and 5 respectively. In 2 patients having Bishop's score 5 LSCS was done due to failed induction. P-Value for Bishop's score at 6 hour, 12 hour was 0.025 and 0.134 respectively which is not significant. $\mathrm{P}-$ Value for Bishop's score at 24 hour is 0.007 , which is significant (Table 4).

In the mifepristone group among 17 primigravida who required oxytocin, 15 delivered vaginaly. LSCS done in 2 cases due to failed induction. Rest 5 delivered vaginaly without oxytocin augmentation. In PGE2 gel 18 primigravida required oxytocin. 13 delivered by normal labour and 5 undergone LSCS.

Table 1: Baseline characteristics of study population.

\begin{tabular}{|lll|}
\hline Parameter & Group-I & Group-II \\
\hline Age(years) & $3(6 \%)$ & $2(4 \%)$ \\
\hline$<20$ & $20(40 \%)$ & $20(40 \%)$ \\
\hline $20-24$ & $22(44 \%)$ & $26(52 \%)$ \\
\hline $25-29$ & $4(8 \%)$ & $3(6 \%)$ \\
\hline $30-34$ & $1(2 \%)$ & $0(0 \%)$ \\
\hline$\geq 35$ & & \\
\hline Parity & $22(44 \%)$ & $24(48 \%)$ \\
\hline Primi & $28(56 \%)$ & $26(52 \%)$ \\
\hline Multi & & \\
\hline Gestational age & $22(44 \%)$ & $20(40 \%)$ \\
\hline $37-40$ week & $28(56 \%)$ & $30(60 \%)$ \\
\hline$>40$ week & & \\
\hline Indication for induction & & \\
\hline $\begin{array}{l}\text { Postdated, uncomplicated } \\
\text { pregnancy with CPD ruled } \\
\text { out }\end{array}$ & $16(32 \%)$ & $17(34 \%)$ \\
\hline Oligohydramnious & $15(30 \%)$ & $13(26 \%)$ \\
\hline FGR (mild) & $5(10 \%)$ & $4(8 \%)$ \\
\hline Twin (1 ${ }^{\text {st }}$ twin vertex) & $2(4 \%)$ & $3(6 \%)$ \\
\hline IUFD (41 weeks) & $4(8 \%)$ & $5(10 \%)$ \\
\hline GDM with controlled sugar & $2(4 \%)$ & $2(4 \%)$ \\
\hline PIH (GHTN) & $4(8 \%)$ & $3(6 \%)$ \\
\hline Others (congenital anomaly) & $2(4 \%)$ & $3(6 \%)$ \\
\hline
\end{tabular}

In mifepristone group, 13 multipara not required oxytocin, 12 delivered by labour natural. Only 1 case undergone $\mathrm{CS}$ due to fetal distress out of 15 multi requiring oxytocin. In PGE2 gel, 7 multigravida delivered vaginaly without oxytocin augmentation. Out of 19, who required augmentation with oxytocin 3 undergone LSCS due to fetal distress and rest delivered vaginaly. In mifepristone and PGE2 group, both primi multi require oxytocin for vaginal delivery. In PGE2 gel group, 12 primi and 10 multi received repeat PGE2 gel, among which 4 had cesarean section because of fetal distress $(2$ cases) fetal distress and failed induction ( 2 cases) (Table 5).

Table 2: Bishop score at the start of study.

\begin{tabular}{|lllll|}
\hline \multirow{2}{*}{ Score } & Group-I & \multicolumn{3}{c|}{ Group-II } \\
\hline Primi & Multi & Primi & Multi \\
\hline $\mathbf{1}$ & $2(2 \%)$ & - & - & - \\
\hline $\mathbf{2}$ & $2(4 \%)$ & $1(2 \%)$ & $4(8 \%)$ & $4(8 \%)$ \\
\hline $\mathbf{3}$ & $3(6 \%)$ & $6(12 \%)$ & $5(10 \%)$ & $5(10 \%)$ \\
\hline $\mathbf{4}$ & $6(12 \%)$ & $5(10 \%)$ & $5(10 \%)$ & $5(10 \%)$ \\
\hline $\mathbf{5}$ & $6(12 \%)$ & $8(16 \%)$ & $6(12 \%)$ & $7(14 \%)$ \\
\hline
\end{tabular}

Shortest drug administration to delivery interval in mifepristone group was 13 hours $30 \mathrm{~min}$ and in PGE2 gel group was 11 hours $48 \mathrm{~min}$ (Table 6).

Duration of 2nd and 3rd stage of labour were all most same in both group with statistically not significant. Duration of 1st stage was shorter in PGE2 gel group with statistical significance. Drug administration to delivery interval was shorter with PGE2 gel group with statistical significance (Table 7).

In mifepristone group $36 \%$ of primi and $46 \%$ of multi delivered by natural labour. 1 patient in each delivered by outlet forceps. 2 multi and 1 primi delivered by vacuum application and rest undergone LSCS (8\%). In PGE2 gel group, $17(34 \%)$ primi and $20(40 \%)$ multi were delivered vaginaly. 1 patient in each parity delivered by outlet forceps. vacuum application was as gr-I. Total $8(16 \%)$ undergone LSCS (Table 8).

In the mifepristione group $2(4 \%)$ primigravida were delivered by cesarean section of which $1(2 \%)$ was done for failed induction and another $1(2 \%)$ for fetal distress whereas in multigravida $2(4 \%)$ were delivered by caesarean with indication of fetal distress.

In the PGE2 gel group among $5(10 \%)$ primigravida delivered by cesarean, $2(4 \%)$ were done for failed induction and $3(6 \%)$ were done for fetal distress whereas in multigravida $3(6 \%)$ were delivered by cesarean section out of which $2(4 \%)$ were done for fetal distress and other 1 (2\%) for failed induction (Table 8).

Maternal complications like fever was more in cerviprime group $10 \%$ compared to $4 \%$ in mifepristone group. 4 (8\%) cases had abdominal cramp in mifepristone group whereas 2 cases developed tachysystole in cerviprime group. There was no PPH or puerpereal sepsis in both group (Table 9).

NICU admission was $16 \%$ in PGE2 gel as compared to $8 \%$ in mifepristone group. In PGE2 gel $5(10 \%)$ neonate were found to have fetal distress where as it was $4 \%$ in 
mifepristone group. But there was no neonatal mortality in both groups. APGAR score at 1 minute and 5 minutes were similar in both groups (Table 9).

Table 3: Favourability of Bishop's score at 6 hour.

\begin{tabular}{|c|c|c|c|c|c|c|}
\hline \multirow{2}{*}{ Score at $6 \mathrm{hr}$} & \multicolumn{3}{|l|}{ Group-I } & \multicolumn{3}{|l|}{ Group-II } \\
\hline & Primi & Multi & Total & Primi & Multi & Total \\
\hline$<6$ & $5(10 \%)$ & 0 & $5(10 \%)$ & $12(24 \%)$ & $10(20 \%)$ & $22(44 \%)$ \\
\hline$\geq 6$ & $17(34 \%)$ & $28(56 \%)$ & $45(90 \%)$ & $12(24 \%)$ & $16(32 \%)$ & $28(56 \%)$ \\
\hline
\end{tabular}

Table 4: Favourability of Bishop Score.

\begin{tabular}{|lllllll|}
\hline Bishop Score & Group & Number & Mean & Std. deviation & Std. error mean & P-value \\
\multirow{2}{*}{ Bishop score at start } & Group-I & 50 & 3.46 & 1.358 & 0.192 & 0.169 (NS) \\
\cline { 2 - 7 } & Group-II & 50 & 3.08 & 1.383 & 0.196 & 0.147 \\
\hline \multirow{2}{*}{ Bishop score at 6 hour } & Group-I & 50 & 6.24 & 1.041 & 0.256 (NS) \\
\cline { 2 - 7 } $\begin{array}{l}\text { Gishop score at 12 } \\
\text { hour }\end{array}$ & Group-II & 50 & 5.96 & 1.384 & 0.196 & 0.134 (NS) \\
\cline { 2 - 7 } $\begin{array}{l}\text { Bishop score at 24 } \\
\text { hour }\end{array}$ & Group-II & 43 & 9.43 & 1.395 & 0.203 & 0.269 \\
\cline { 2 - 7 } & Group-I & 9 & 10 & 1.936 & 0.655 & 0.007 (S) \\
\hline
\end{tabular}

Table 5: Augmentation with oxytocin.

\begin{tabular}{|lllllll|}
\hline Augmentation & Group-I & Multi & Total & Proup-II & Multi & Total \\
\hline Required & $17(34 \%)$ & $15(30 \%)$ & $32(64 \%)$ & $18(36 \%)$ & $19(38 \%)$ & $37(74 \%)$ \\
\hline Not required & $5(10 \%)$ & $13(26 \%)$ & $18(36 \%)$ & $6(12 \%)$ & $7(14 \%)$ & $13(26 \%)$ \\
\hline
\end{tabular}

Table 6: Drug administration to delivery interval.

\begin{tabular}{|lll|}
\hline Drug administration to delivery interval (hours) & Group-I & Group-II \\
\hline $\mathbf{1 0 - 1 2 . 5 9}$ & 0 & 11 \\
\hline $\mathbf{1 3 - 1 5 . 5 9}$ & 12 & 12 \\
\hline $\mathbf{1 6 - 1 8 . 5 9}$ & 12 & 7 \\
\hline $\mathbf{1 9 - 2 1 . 5 9}$ & 7 & 9 \\
\hline $\mathbf{2 2 - 2 4 . 5 9}$ & 7 & 3 \\
\hline $\mathbf{2 5 - 2 7 . 5 9}$ & 8 & 0 \\
\hline
\end{tabular}

Table 7: Comparison of duration of labour between the PGE2 and Mifepristone group at various stages.

\begin{tabular}{|llll|}
\hline Duration of Labour & Group-I (46) Mean+SD & Group-II (42) Mean+SD & P-value \\
\hline 1st stage (hr) & $11.6124 \pm 2.43722$ & $9.2236 \pm 1.24753$ & 0.0002 (S) \\
\hline 2nd stage (min) & $26.67 \pm 4.926$ & $26.71 \pm 5.584$ & 0.971 (NS) \\
\hline 3rd stage (min) & $5.030 \pm 0.9789$ & $5.186 \pm 1.0094$ & 0.466 (NS) \\
\hline DD Interval (hr) & $19.4065 \pm 4.30411$ & $15.9769 \pm 3.50301$ & 0.0002 (S) \\
\hline
\end{tabular}

Table 8: Mode of delivery.

\begin{tabular}{|lllllll|}
\hline Mode of delivery & Group I & Multi & Total & Proup II & Multi & Total \\
\hline Labour natural & $18(36 \%)$ & $23(46 \%)$ & $41(82 \%)$ & $17(34 \%)$ & $20(40 \%)$ & $37(74 \%)$ \\
\hline Outlet forceps & $1(2 \%)$ & $1(2 \%)$ & $2(4 \%)$ & $1(2 \%)$ & $1(2 \%)$ & $2(4 \%)$ \\
\hline Vacuum delivery & $1(2 \%)$ & $2(4 \%)$ & $3(6 \%)$ & $1(2 \%)$ & $2(4 \%)$ & $3(6 \%)$ \\
\hline LSCS & $2(4 \%)$ & $2(4 \%)$ & $4(8 \%)$ & $5(10 \%)$ & $3(6 \%)$ & $8(16 \%)$ \\
\hline Indication of LSCS & & & & & & \\
\hline Failed induction & $1(2 \%)$ & 0 & $1(2 \%)$ & $2(4 \%)$ & $2(4 \%)$ & $4(8 \%)$ \\
\hline Fetal distress & $1(2 \%)$ & $2(4 \%)$ & $3(6 \%)$ & $3(6 \%)$ & $1(2 \%)$ & $4(8 \%)$ \\
\hline
\end{tabular}


Table 9: Complications.

\begin{tabular}{|lll|}
\hline $\begin{array}{lll}\text { Complications } & \text { Group } & \text { Group } \\
\text { I }\end{array}$ \\
\hline Maternal complications & & \\
\hline Fever & $2(4 \%)$ & $5(10 \%)$ \\
\hline GI symptoms & $3(6 \%)$ & $3(6 \%)$ \\
\hline Abdominal cramps & $4(8 \%)$ & - \\
\hline Tachysystole & - & $2(4 \%)$ \\
\hline PPH & - & - \\
\hline Puerperal sepsis & - & - \\
\hline Neonatal complications & & \\
\hline Respiratory distress & $1(2 \%)$ & $3(6 \%)$ \\
\hline Meconium aspiration syndrome & $2(4 \%)$ & $5(10 \%)$ \\
\hline Transient tachypnoea of newborn & $1(2 \%)$ & - \\
\hline
\end{tabular}

\section{DISCUSSION}

Research continues to invent and modify doses of different drugs for cervical ripening. Mifepristone has been used to induce labour or to allow pregnancy to be terminated. In present study, we opted for $200 \mathrm{mg}$ mifepristone as a tablet and observation period was of 24 hours similar to the Wing et al, Arumugalselvi et al study and Salitha et al..$^{5-7}$ In Wing et al mifepristone was compared with placebo whereas in others with PGE2 gel like in our study.

$42(84 \%)$ and $46(92 \%)$ both primi and multigravida were between the age group of 20-29 years in mifepristone group and dinoprostone group respectively accounting for $88 \%$ in our study (Table 1). This study correlates with randomized controlled trial conducted by Wing et al in which $88 \%$ of the patients were in the age group of $21-30$ years. ${ }^{5}$ It also correlates with a randomized controlled trial by Saranya et al $85 \%$ of the patients were in 21-29 years. $^{8}$

Although term gestation between (37-42) weeks were included but maximum cases were of GA between 40-42 weeks (Table 1) in our study which is similar to study of Fathima et al and Su et al in 1996. ${ }^{9,10}$

Patients with bishop's score less than 6 were included in the study group (Table 2). Similar study was done by Bashutheen et al in which Bishop's score of 1-6 were included. ${ }^{11}$ According to another study by Deepika et al $400 \mathrm{mg}$ mifepristone was given with Bishop's score $<6 .{ }^{12}$ In our study, mean Bishop's score at start of the study was 3.27, which was comparable with Saranya study, where mean bishop's score at start was 2.72 and Yellikar et al with mean bishop's score $2.02 . .^{8,13}$

Favourable Bishop score of 6 or more at augmentation was seen in $90 \%$ in Group-I and 56\% in Group-II (Table 3) which was consistent with Sah et al, Saranya et al, Arumugaselvi. ${ }^{6,8,13}$ Study done by Sah et al in 2018 with $76 \%$ in mifepristone gr and $56 \%$ in PGE2 gr with $200 \mathrm{mg}$ mifepristone. It was $96.6 \%$ in mifepristone gr and $76.6 \%$ in PGE2 gr according to the study done by Gaikwad et al. ${ }^{15}$ This was contrary to study done by Sailatha et al in which improvement in Bishop score was significantly better with dinoprostone group as compared to mifepristone group. ${ }^{7}$

The need for augmentation with oxytocin was $64 \%$ in the mifepristone group and $74 \%$ in PGE2 group (Table 5) which was similar with Arumugaselvi et al where $66 \%$ in mifepristone gr and $78 \%$ in PGE2 gr required oxytocin. Similar study was done by Wing et al where $67 \%$ in mifepristone group required oxytocin for augementation as compared to placebo. ${ }^{6,5}$ According to Salitha et al oxytocin requirement was less in mifepristone group $(24 \%)$ as compared to cerviprime group $(38 \%){ }^{7}$

Shortest drug administration to delivery interval in our study was 13 hours $30 \mathrm{~min}$ in mifepristone gr and 11 hour 48 min in PGE2 gr (Table 6) which was consistent with Arumugaselvi et al. ${ }^{6}$ In that study, shortest drug administration to delivery interval was 12 hour 5 min and 5 hour 54 min in mifepristone and PGE2 gr respectively.

In our study the mean induction delivery interval in Mifepristone group was 19.40 hours and PGE2 15.97 (Table 7) which is comparitively less than the randomized controlled trial conducted by Sailatha et al, in which mean induction delivery interval was 20.3 hours for mifepristone and 11.5 hours in PGE2 gr. ${ }^{7}$ The induction to delivery interval in mifepristone group was more as it takes about 24-48 hours for the drug to have priming effect on the cervix. According to Arumugaselvi et al, it was 18.73 hours and 11.47 hours in mifepristone and PGE2 respectively. ${ }^{6}$ A study was done by Bama et al in which 28.6 hour in mifepristone group and 35.44 hour in placebo group. ${ }^{16}$ Induction to delivery interval was shorted in mifepristone group compared to dinoprostone group in Sah et al study which was contrast to all above study. ${ }^{14}$

The criteria taken for the success of induction was vaginal delivery. In our study the rate of vaginal delivery was $92 \%$ in Mifepristone group (40\% primigravida and $52 \%$ multigraavida) and $84 \%$ in PGE2 gr (38\% primi and $46 \%$ ) (Table 8). The results were consistent with Bama et al study where the vaginal delivery is $96 \%$ in mifepristone gr and $72 \%$ in PGE2 gr. ${ }^{16}$ Success rate was $87.5 \%$ in mifepristone group in Wing et al study. ${ }^{5}$

Rate of LSCS in mifepristone group in our study was $8 \%$ and $16 \%$ in dinoprostone group (Table 8). Similar findings were noted by Sah et al and Shanitha et al. ${ }^{9,14}$ In this aspect our study is consistent with Sailatha et al study in which LSCS was done for failed induction $(4 \%)$ in mifepristone gr and $10 \%$ in PGE2 gr. ${ }^{7}$ Gaikwad et al was also found higher of LSCS in dinoprostone group. ${ }^{15}$ According to Hapangama and Neilson, mifepristone treated women are less likely to undergo CS as a result of failed induction. ${ }^{17}$ The most common indication for LSCS was fetal distress in mifepristone group $(6 \%)$ 
where as both fetal distress $(8 \%)$ and failed induction $(8 \%)$ in dinoprostone group (Table 8). Fetal distress was most common indication for LSCS in the study of Shanitha et al and Sah et al. ${ }^{9,14}$ Gaikwad et al in their study found that the most common indication for LSCS was fetal distress in mifepristone group (8\%) and most common indication for LSCS was failed induction in dinoprostone group (28\%). ${ }^{15}$

None of the patient of mifepristone gr had hypertonus or tachysystole which was comparable with Wing et al. ${ }^{5} 2$ patient in PGE2 gr had tachysystole (Table 9). This was in contrast to study conducted by Giacalone et al, in which Mifepristone treated group had higher rates of uterine hyperstimulation and tachysystole. ${ }^{18}$

In our study, none of our study population had major complications like rupture uterus, chorioamnionitis, postpartum hemorrhage, puerperal sepsis (Table 9). Only minor side effect like nausea, vomiting, abdominal pain which is similar to Elliot et al and Lelaideir et al. ${ }^{19,20} \mathrm{~A}$ total of $18 \%$ study population had minor complications like nausea, vomiting, abdominal cramps in mifepristone group and $8 \%$ in PGE2 group. In this aspect our study is consistent with the study conducted by Stenlund et al study. ${ }^{21}$

Meconium passage was encountered in $4 \%$ and NICU admission was $8 \%$ in mifepristone group and meconium passage was $10 \%$ and NICU admission was $16 \%$ in PGE2 gel group. APGAR score at 1 minute and 5 minute were similar in both groups. But there was no neonatal mortality in both groups (Table 9). In this aspect, our study is consistent with study conducted by Gaikwad et al, in which $6 \%$ and $14 \%$ babies admitted in mifepristone and PGE2 gr respectively. ${ }^{14}$ It was contrast to study by Sah et al where five neonate $(10 \%)$ in mifepristone group one $(2 \%)$ cases in dinoprostone group required NICU admission. ${ }^{13}$

\section{Limitations}

Limitations of this study is 24 hour study for induction is very lengthy process and only limited indicated cases are taken for induction.

\section{CONCLUSION}

The safety and efficacy of oral mifepristone as a preinduction cervical ripening agent is assessed in this study and compared with PGE2 gel. 100 antenatal mothers admitted at MKCG Medical College Hospital, who needed elective induction, satisfying the inclusion criteria were recruited into two groups and each were given oral mifepristone $200 \mathrm{mg}$ or endocervical PGE2 gel $0.5 \mathrm{mg}$ for cervical ripening and augmented with oxytocin. This study documents the success of induction, details of parturition, maternal and neonatal outcome. This study revealed that mothers in both groups had Bishop score of 0 to 5 at the start of study. $90 \%$ (42\% primigravida and $48 \%$ multigravida) had favourable Bishop score in mifepristone group whereas only $56 \%$ ( $28 \%$ primigravida and $28 \%$ multigrovida) in PGE2 gel group. Duration of 1st stage and DD interval is shorter in PGE2 gr which is not significant.

Duration of 2nd and 3rd stage is shorter in mifepristone gr which is not significant. The outcome of induction in this study reveals that the mifepristone was successful in $82 \%$ in achieving vaginal delivery whereas PGE2 gel was successful in $74 \%$. Cesarean section rate was $8 \%$ in mifepristone group whereas $16 \%$ in PGE2 gel group. $2 \%$ of failed induction in mifepristone gr where as it was $8 \%$ in PGE2 gr. Another indication of CS in both groups was fetal distress which comprises $6 \%$ and $8 \%$ in mifepristone and PGE2 gr respectively. Maternal complications were similar in both groups. Neonatal complications and neonatal admissions were lesser in mifepristone group.

Oral mifepristone is very safe and an effective drug for preinduction cervical ripening. It has an added advantage of ease of administration, better patient compliance and acceptance, reduced oxytocin requirement, shorter duration of II, III stages of labour with an overall success rate of $82 \%$. The drug has no untoward side effects on uterine contraction and no major maternal complications and safe in neonatal outcome. Hence mifepristone offers advantages over PGE2 gel which is currently used for preinduction cervical ripening.

\section{Funding: No funding sources}

Conflict of interest: None declared

Ethical approval: The study was approved by the Institutional Ethics Committee

\section{REFERENCES}

1. Arulkumaran, Leonie K, Penna K, Rao B. The management of Labour. Second edition. Wiley Online Library. 2007:11,12,14,281,292-6.

2. Cunnigham FG, Leveno KJ, Bloom SL, Hauth JC, Gilstrap LC. Williams Obstetrics. 22 ${ }^{\text {nd }}$ Edition, McGraw-Hill Education. 2006:168,536.

3. Cunnigham FG, Leveno KJ, Bloom SL. Induction and augmentation of labor. In: William's obstetrics. 24th edition. McGraw Hill Professional. 2014:525.

4. Heikinheimo O, Kekkonen R, Lahteenma P. The pharmacokinetics of mifepristone in humans reveal insights into differential mechanisms of antiprogestin action. Contraception. 2003;68(6):421-6.

5. Wing DA. Mifepristione for pre induction cervical ripening beyond 41 weeks gestation: a randomized controlled trial. Obstet Gynecol. 2000;96(4):543-8.

6. Arumugaselvi B, Sujathasenthil S, Anandan H, Comparative study of oral mifepristone and endocervical prostaglandins E2 Gel as preinduction cervical ripening agent in parturation. Int J Sci Stud. 2017;5(3):129-33.

7. Sailatha R, Famida AM, Chellaiyan VGD, Vijayalakshmi K, Sathiya S, Renuka S. Mifepristone: 
an alternate to dinoprostone in induction of labour. Int J Reprod Contracept Obstet Gynecol. 2017;6:1880-4.

8. Saranya A, Pradeeba S. Comparative analysis of safety, efficacy and fetomaternal outcome following induction of labour with mifepristone vs intracervical dinoprostone gel. Indian J Res. 2019;(3):10-24.

9. Shanitha F, Nayak SR, Bharathi R, Gandhi P, Shameem VPA. Mifepristone in the induction of labour at term. Int $\mathbf{J}$ Pharm Biomed Res. 2013;4(3):164-6.

10. Su H, Li E, Weng L. Mifepristone for induction of labor. Zhonghua $\mathrm{Fu}$ Chan $\mathrm{Ke} \mathrm{Za}$ Zhi. 1996;31(11):676-80.

11. Bashutheen NS, Sharon M. A study of intracervical PGE2 gel for cervical ripening and induction of labour. Int J Contemp Med Res. 2018;5(3):C4-C7.

12. Deepika N, Kumar A. Mifepristone for cervical ripening and induction of labour. J obstet Gynecol India. 2018;5:15-29.

13. Yellikar K, Deshpande S, Deshpande R, Lone D. Safety and efficacy of oral mefipristone in preinduction cervical ripening and induction of labor in prolonged pregnancy. J Obstet Gynaecol India. 2015;65(4):221-5.

14. Sah MK, Padhye SM. Mifepristone versus intracervical prostaglandin E2 gel for cervical ripening in primigravid patients at term. Int J Reprod Contracept Obstet Gynecol. 2014;4:43-7.
15. Vidya G, Bilsi M, Puri M. Comparative analysis of safety, efficacy and fetomaternal outcome of induction of labour with mifepristone versus intracervical dinoprostone gel. RJPBCS. 2014;5(2):611.

16. Ramesh B, Vidyaravi, Mareeswari. Role of oral mifepristone as acervical priming agent for induction of labour. J Evid Based Med Healthc. 2018;5(3):2805.

17. Hapangama D, Nielson JP. Mifepristone for induction of labour. Cochrane Database Syst Rev. 2009;3:CD002865.

18. Giacalone PL. Cervical ripening with mifepristone before labour induction: a randomized study. Obstet Gynecol. 1998;92:487-92.

19. Elliot P. The effects of mifepristone on cervical ripening and labour induction in primigravida. Obstet Gynecol. 1998;92(5):804-9.

20. Lelaider C. Mifepristone for labour induction after previous caesarian section. Br J Obstet Gynaecol. 1994;101(6):501-3.

21. Stenlund PM, Ekman G, Aedo AR, Bygdeman M. Induction of labor with mifepristone-a randomized, double-blind study versus placebo. Acta Obstet Gynecol Scand. 1999;78(9):793-8.

Cite this article as: Mohapatra S, Samarpita. A comparative study on the role of oral mifepristone and endocervical prostaglandin as preinduction cervical ripening agent. Int J Reprod Contracept Obstet Gynecol 2021;10:215-21. 